\title{
A Model for Tax Level Influence on Population Dynamics
}

\author{
$1^{\text {st }}$ M Subhan \\ Department of Mathematics \\ Universitas Negeri Padang \\ Padang, Indonesia \\ 13subhan@fmipa.unp.ac.id
}

\begin{abstract}
Disparity and poverty is one important problem in most countries in the world. Taxation aims at meeting public needs and may be spent by government to overcome the economic problems. However, there is a dilemma about the level of tax that government's stated. A mathematical model could give some understanding about this phenomenon. The goal of this research is to obtain a mathematical model that can describe the influence of tax level on economic population dynamic. The research is theoretical based on relevance references. From the analytical analysis and numerical simulation, we conclude that both high and low level tax have the similar dynamical behaviour, but the high level of tax bring the better proportion of welfare equilibrium.
\end{abstract} level.

Keywords-Mathematical model, population dynamic, tax

\section{INTRODUCTION}

Today, poverty is one of the most important problems in the world. This is not only the problem of poor people living in specific regions but also the problem of all people in general. Poverty is expected to decrease as the welfare level increases. The World Bank predicts that extreme poverty will disappear until 2030 but mentions significant hesitations in achieving this objective. Even though extreme poverty will have actually disappeared in 2030, the deep gap between the richest $20 \%$ and the poorest $20 \%$ will continue to maintain its presence. There are many reasons for poverty arising from individuals such as illiteracy, inexperience, and laziness. However, there are many reasons for poverty beyond the individual such as the management of the capital by a small group of people. While the capital continuously increases under the control of a narrow group, poor community deprived of increasing welfare benefits from it slightly and too late [1]. Government use tax as instrument to financing their program, which most of it will used to distribute welfare. Though all taxes have disincentive effects, taxes that reduce incentives to invest in human or physical capital and innovation are particularly damaging [2]. Previous research shows that zakat in Islamic tradition may replace tax function to distribute welfare and reduce level of poverty [3].

Tax systems is used by government and primarily objective is to finance their public program. Tax is collected from individual and business venture domiciled in their country and they will receive the benefit of tax indirectly. Tax systems also create equity and welfare distribution. Tax also gives effect to people's saving and companies' business decision, creating jobs, and development of human index. All of these purpose and tax levels will reflect in overall living standards. [4]. The Scandinavian countries which have high level countries have higher living standard than countries that have low level of tax.

In the current setup, higher tax rates lead to a larger informal economy. An increase in reduces profits of formal managers more strongly than expected profits of informal managers. Formal managers' tax burden increases to the full extent of the higher tax rate, whereas the increase in the informal managers' tax burden is downscaled by the probability of getting caught [5].

Mathematical model is a mathematical tool which provides some inside view of real-world phenomenon. In this article, we will build a deterministic model that can describe the influence of tax level on wealth of a country especially the dynamic of economic population.

\section{RESEARCH METHODS}

This article contains a mathematical model of population dynamics under influence of tax level. We determine the effects of some factors for welfare distribution. The research's findings are developed by qualitative research methods. We build some theories which explain the relation among variables and parameters. Using relevance references, we build a mathematical model, then analyse and interpreting it. We use some numerical simulations to justify the result.

\section{DISCUSSION}

\subsection{The model}

We begin constructing a mathematical model by dividing the population into three compartments, which are:

$W$ : The number of wealthy individuals.

$X$ : The number of poor individuals 
$N$ : The number of neither wealthy nor poor individuals; we name it neutral population

The total population is $T$ where $T=W+X+N$

Some assumptions that are used in this model are:

1. Every new-born is belong to the $N$ compartment.

2. Individual from wealthy population cannot change into poor population directly, and also the contrary. They must become 'neutral' population in between.

3. The change from each compartment is caused by economic growth, influence of tax collected, and business failures.

4. The total population is constant since the birth and death rate are equal and no migration considered.

5. The rate of changes affected by tax, economic growth, and business failures are constant and equal for all compartments. Some research exclaimed that economic growth can reduce poverty [6,7], but there also some poverty increases. [8]

6. There is threshold value or optimal level of tax.

Using all these assumptions, we set some parameter needed in this model. We use $\mu$ to represent the birth and also death rate. The parameter $\varepsilon$ is used to represent the rate of change into wealthier population as affected by economic growth. The rate of business failures is represented by $\gamma$. Rate of change from lower economic population into higher is slightly affected by a factor resulted from different between tax level and threshold value. We use $\delta$ to represent the factor, where its value positive if the tax level is higher and negative if the tax level is lower. Because it only affects slightly, its absolute value is less than $\varepsilon$ and $\gamma$.

From the assumptions, we build the first initial model as follows:

$$
\begin{gathered}
\frac{d W}{d t}=(\varepsilon+2 \delta) N-(\gamma+\delta+\mu) W \\
\frac{d X}{d t}=(\gamma-\delta) N-(\varepsilon+\delta+\mu) X \\
\left.\frac{d N}{d t}=\mu T+(\varepsilon+\delta) X+(\gamma+\delta) W-(\delta+\varepsilon+\mu) N\right)
\end{gathered}
$$

We reduce the system by one equation because of constant population assumption. We introduce new scaling variables

$$
R=\frac{W}{T}, P=\frac{X}{T}, S=\frac{N}{T}
$$

which governed by equation $S=1-P-R$. The variables, our concern most, are $R$ (proportion of wealthy/rich population) and $P$ (proportion of poor population). So, the new model is:

$$
\begin{aligned}
& \frac{d R}{d t}=(\varepsilon+2 \delta)(1-R-P)-(\gamma+\delta+\mu) R \\
& \frac{d P}{d t}=(\gamma-\delta)(1-R-P)-(\varepsilon+\delta+\mu) P
\end{aligned}
$$

As a proportion model, all variables used are feasible on $[0,1]$. For initial validation, we evaluate the behaviour of the variables on their boundaries, and we have both $\frac{d P}{d t}, \frac{d R}{d t}$ are greater than zero when the variable is zero, and both $\frac{d P}{d t}, \frac{d R}{d t}$ are smaller than zero when the variable is one. That give us the conclusion of well-defined and applicable of the model.

\subsection{Model analysis and interpretation}

For the first step in analysing model, we find the fixed point. This system has the only fixed point

$$
\begin{aligned}
& R_{0}=\frac{(\delta+\varepsilon)^{2}+\delta(\delta+\varepsilon+2 \mu)+\varepsilon \mu}{\delta(\delta+2 \varepsilon+\gamma+3 \mu)+\varepsilon(\gamma+\mu)+(\delta+\varepsilon)^{2}+(\gamma+\mu)^{2}} \\
& P_{0}=\frac{(\gamma-\delta)(\gamma+\delta+\mu)}{\delta(\delta+2 \varepsilon+\gamma+3 \mu)+\varepsilon(\gamma+\mu)+(\delta+\varepsilon)^{2}+(\gamma+\mu)^{2}}
\end{aligned}
$$

Next, we determine the characteristic of this fixed point by linearizing the system around the fixed point. The Jacobian matrix of this system is

$$
\left[\begin{array}{cc}
-(\gamma+3 \delta+\varepsilon+\mu) & -(2 \delta+\varepsilon) \\
\delta-\gamma & -(\gamma+\varepsilon+\mu)
\end{array}\right]
$$

which has the eigenvalues

$$
-\frac{1}{2}(\gamma+3 \delta+\varepsilon+\mu) \pm \frac{1}{2} \sqrt{\delta^{2}+4 \varepsilon \gamma+8 \delta \gamma-4 \delta \varepsilon}
$$

When the economic growth is positive, $\varepsilon>0$, both eigenvalues are negative in their real parts. We conclude that the fixed point is stable asymptotic. Considering the poverty reduction effort, we get the threshold value of $d P$ as

$$
\frac{N}{P}=\frac{\varepsilon+\delta+\mu}{7-\delta}
$$

It means that proportion of poor individuals will decrease when ratio between neutral population $N$ and poor population $R$ is below $\frac{\varepsilon+\delta+\mu}{\gamma-\delta}$ and will increase when the ratio is above $\frac{\varepsilon+\delta+\mu}{\gamma-\delta}$.

\subsection{Numerical simulation}

In numerical simulation, we will use this set of parameter values

$$
\delta=0.0000054795 / \text { day, } \gamma=0.000342466 / \text { day, }
$$
$\varepsilon=0.001369863 /$ day, $\mu=0.000547945 /$ day,

In this parameters setting, we have the fixed point $(0.5773471433,0.05379218176)$ which represent 
proportion of rich poor are respectively around $58 \%$ and $5 \%$. The trajectories of the system are relevant to the analysis before as seen in Figures 1 and 2.

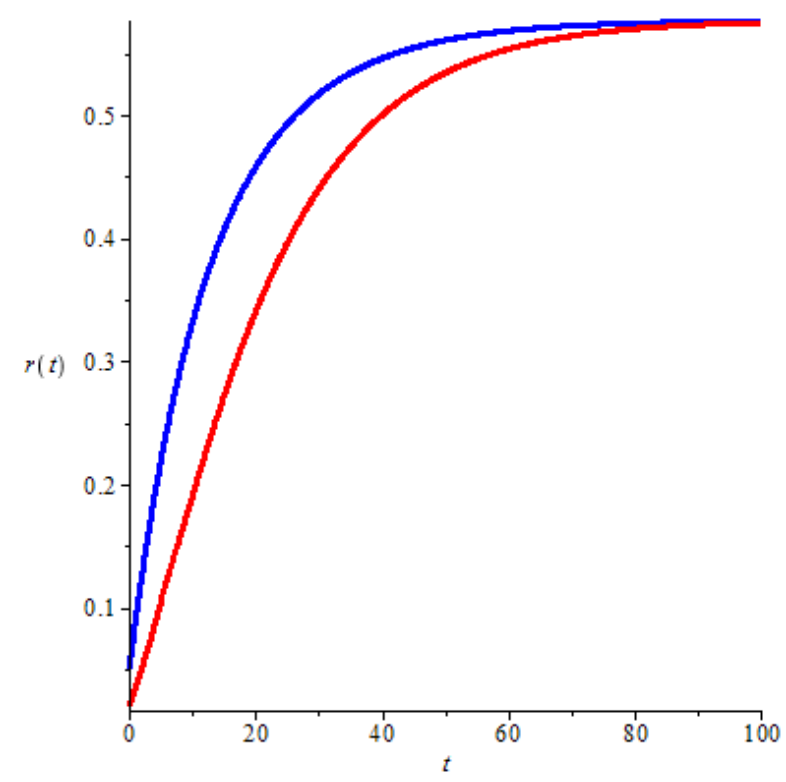

Fig. 1. The trajectory of rich proportion population $R$ over 100 years in case of high level tax for initial value $(R(0), P(0)):(0.05,0.15)$ and $(0.02,0.7)$

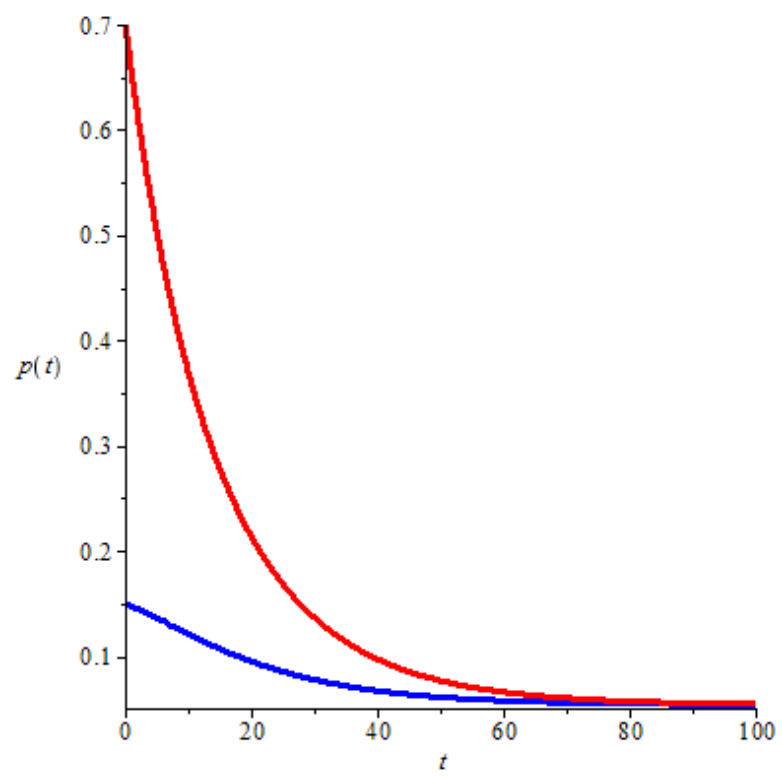

Fig. 1. The trajectory of poor proportion population $P$ over 100 years in case of high level tax for initial value $(R(0), P(0)):(0.05,0.15)$ and $(0.02,0.7)$.
When the tax level is low, the behaviour of the system quite the same, but the proportion of rich-poor become about $32 \%$ and $26 \%$ respectively. The only fixed point of the system is also stable as reflected by trajectories in Figures 3 and 4 .

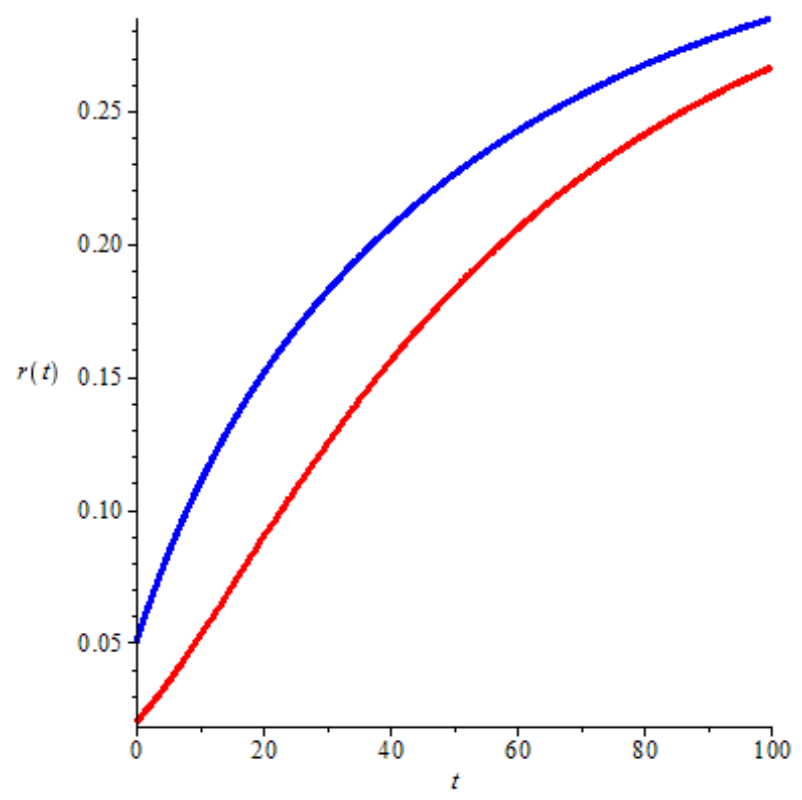

Fig. 3 The trajectory of rich proportion population ${ }^{R}$ over 100 years in case of low level tax for initial value $(R(0), P(0)):(0.05,0.15)$ and $(0.02,0.7)$

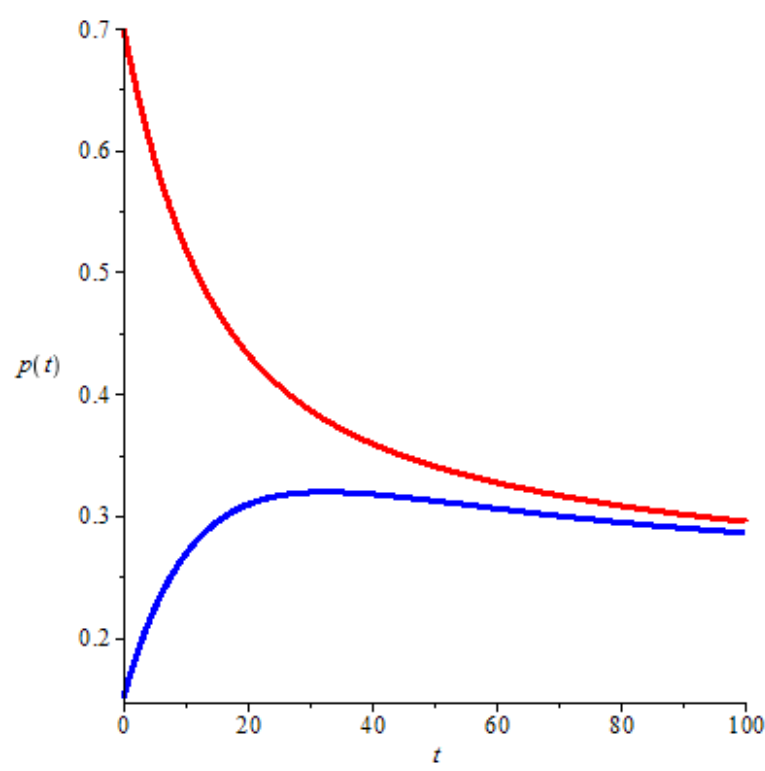

Fig. 4. The trajectory of poor proportion population $P$ over 100 years in case of low level tax for initial value $(R(0), P(0)):(0.05,0.15)$ and $(0.02,0.7)$.

\section{CONCLUSION}

The population dynamic model shows that if tax level is high, then the ratio of rich and poor will become lower and the gap between rich and poor will decrease. In case of tax level is low, the proportion of rich-poor is still very high and the country must have a correct policy to use tax in 
finance their program. Model analysis and numerical simulation, for both case, show that there is stable welfare equilibrium.

\section{REFERENCES}

[1] Kuzudisli A, Fight against poverty from the Islamic point of view: the wealth distribution and share Economics World, Vol. 5 pp. 9-15, 2017

[2] Subhan M, "A Mathematical Model of Economic Population Dynamics in a Country That Has Optimal Zakat Management", IOP Conference Series: Materials Science and Engineering, Vol. 335 Issue 1 pp. 012051,2018
[3] Magu M C, The relationship between government revenue and economic growth in Kenya MBA Thesis, 2013

[4] Engen E and Skinner J, "Taxation and Economic Growth National Tax J", Vol. 49 pp. 617-642, 1996.

[5] Kuehn Z, Tax Rates, Governance, and the Informal Economy in High-Income Countries, 2009.

[6] Mahat N I and Warokka A, "Investigation on zakat as an indicator for moslem countries' economic growth", J. Global Business Advancement, Vol. 6, 2013

[7] Sboui F, "Effects of growth and inequality on poverty in Tunisia", Region et Developpement, 35, pp. 57-80, 2012

[8] Paci P, Sasin M J, and Verbeek J, Economic growth, income distribution, and poverty in Poland during transition, Proc. ABCDE Conference, 2004 